\title{
Perbandingan Algoritma Background Subtraction dan Optical Flow Untuk Deteksi Manusia
}

Karina Mariane Kaloh, Vecky C. Poekoel, Muhamad Dwisnanto Putro

Teknik Elektro, Universitas Sam Ratulangi Manado, J1. Kampus Bahu-Unsrat Manado, 95115

13021106046@student.unsrat.ac.id,vecky.poekoel@unsrat.ac.id,dwisnantoputro@unsrat.ac.id

Abstrak - Many algorithms can be used to detect humans. Background subtraction and optical flow are the most popular algorithm. Background subtraction is a process for detecting human objects by comparing two images which is background images that has a object and the other one is not. Images that have objects and images that do not have objects are subtracted to get the whole object without background. Optical flow is the flow of movement from a moving object. The movement of optical flow is obtained from the initial frame to the last frame of a video. Video sample is processed by background subtraction algorithm and optical flow algorithm to determine the best human detection and to know the accuracy from the both algorithm. The experiment using 1 sample video with 3 minutes duration has obtained the results in detecting human presence, using background subtraction algorithm has a truth level $80.56 \%$. And the optical flow algorithm has a truth level of $97.22 \%$. The results of calculating the ammount of humans detected, background subtraction algorithm has a truth level of 2.78\%. While the optical flow algorithm has a truth level of $16.67 \%$.

Keywords: Background subtraction, human detection system, optical flow

Abstrak - Banyak algoritma yang bisa digunakan untuk membuat sistem pendeteksi manusia Algoritma background subtraction dan algoritma optical flow merupakan algoritma yang populer digunakan. Background subtraction adalah proses untuk mendeteksi objek manusia dengan cara membandingkan gambar yang memiliki objek dengan gambar latar belakang yang tidak memiliki objek. Gambar yang memiliki objek dan gambar yang tidak memiliki objek selanjutnya dikurangi agar mendapatkan objek utuh tanpa background. Optical flow adalah aliran pergerakan dari sebuah objek yang bergerak. Pergerakan optical flow didapatkan dari frame awal sampai frame terakhir pada sebuah video. Video sampel rekaman diolah oleh algoritma background subtraction dan algoritma optical flow untuk menentukan pendeteksian manusia yang paling baik serta mengetahui keakuratan dari kedua algoritma tersebut. Pengujian menggunakan 1 video sampel dengan durasi 3 menit, didapatkan hasil dengan menggunakan algoritma background subtraction memiliki tingkat kebenaran sebanyak $80.56 \%$. Sedangkan dengan menggunakan algoritma optical flow memiliki tingkat kebenaran sebanyak $97.22 \%$. Selanjutnya hasil yang didapat dalam menghitung jumlah manusia yang terdeteksi, dengan menggunakan algoritma background subtraction memiliki tingkat kebenaran sebanyak $\mathbf{2 . 7 8 \%}$. Sedangkan dengan menggunakan algoritma optical flow memiliki tingkat kebenaran sebanyak $16.67 \%$.

Kata Kunci: Background subtraction, Optical flow, sistem deteksi manusia

\section{PENDAHULUAN}

Citra digital didapatkan dari sekumpulan gambar maupun dari video. Gambar dan video merupakan hasil rekaman kamera seperti IP Camera, CCTV, Digital Camera, maupun Handphone Camera. Hasil gambar maupun video yang direkam sebuah kamera tidak mempunyai kualitas sampai $100 \%$ maksimal. Penyebab hal tersebut yaitu spesifikasi kamera yang rendah, letak kamera yang tidak tepat, pencahayaan yang kurang, serta terdapat noise atau gangguan pada saat proses perekaman. Kualitas sebuah citra dipengaruhi oleh berbagai faktor. Di luar ruangan, keadaan lingkungan seperti pepohonan yang bergerak karena tiupan angin, cahaya lampu dari gedung/bangunan, lampu jalan, lampu lalu lintas, serta lampu kendaraan bermotor bisa mempengaruhi kualitas citra. Selain itu objek manusia yang terhalang objek lainnya seperti berada di belakang pohon, berada di dalam ruangan, atau di dalam kendaraan seringkali gagal untuk dideteksi citra. Seiring berkembang teknologi, kini teknik pengolahan citra digital dapat telah dikembangkan menjadi computer vision. Computer vision merupakan suatu proses untuk mengolah gambar dan video untuk memperoleh suatu hasil yang bisa dianalisa. Computer vision memiliki fungsi seperti mata manusia yaitu dalam penglihatan. Manusia melihat obyek dengan indra penglihatan (mata), lalu citra obyek diteruskan ke otak untuk diinterpretasi sehingga manusia mengerti obyek apa yang tampak dalam pandangan matanya [1]. Salah satu implementasi computer vision digunakan untuk mendeteksi manusia dan pergerakannya.

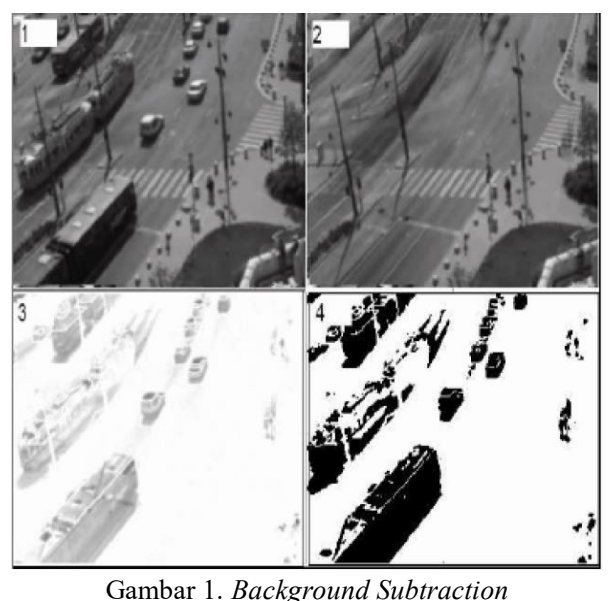

(1-Gambar Sekarang, 2-Background Model, 3-Hasil Background Subtraction, 4-Hasil Background Subtraction Setelah Threshold) [2] 
Sistem deteksi manusia yang berfungsi seperti mata manusia [1] menggunakan gambar atau video untuk mendapatkan informasi seperti letak manusia berdiri, arah manusia menghadap, pergerakan manusia serta kemana arah pergerakan manusia tersebut. Banyak algoritma yang dipakai untuk mendeteksi manusia. Algoritma yang dipakai pada penelitian ini yaitu algoritma background subtraction dan algoritma optical flow. Background subtraction adalah proses untuk mendeteksi objek pada citra dengan cara mengurangi gambar yang memiliki objek dengan sebuah model latar belakang [2]. Gambar 1 adalah gambar dari background subtraction. Optical flow adalah aliran pergerakan dari sebuah objek yang bergerak berdasarkan turunan intensitas cahayanya. Pada ruang 2D, optical flow berarti seberapa jauh suatu piksel citra berpindah diantra dua frame citra yang berurutan. Sedangkan pada ruang 3D, optical flow yaitu seberapa jauh suatu volume piksel (voxel) berpindah pada dua volume yang berurutan. Berdasarkan perubahan intensitas cahaya pada kedua frame citra maupun volume, dilakukan perhitungan turunan. Penyebab terjadinya perubahan intensitas cahaya pada suatu bagian citra disebabkan oleh adanya gerakan yang dilakukan oleh obyek, gerakan sumber cahaya, ataupun perubahan sudut pandang [3]

Pada penelitian ini sampel video rekaman yang didapatkan, diolah oleh algoritma background subtraction dan algoritma optical flow untuk menentukan pendeteksian citra yang paling baik serta mengetahui keakuratan dari algoritma yang mana untuk pendeteksian manusia dan perhitungan jumlah orang yang terdeteksi. Sistem ini akan mengambil data yaitu merekam video di dalam ruangan dengan memilih kondisi pada pagi, siang, sore maupun malam hari dengan kondisi memakai cahaya matahari (tidak memakai lampu) ataupun memakai lampu [1]. Untuk mengetahui apakah terdapat gerakan atau tidak sistem pendeteksi gerakan akan membandingkan antara frame satu dengan frame lain dari gambar-gambar yang berurutan atau video. Manusia yang terdeteksi di frame akan diumpamakan sebagai objek bergerak. Proses selanjutnya yaitu mengolah lagi gambar atau video untuk mendapatkan jumlah orang. Sistem pendeteksi gerakan ini berperan utama untuk mendeteksi ada atau tidak adanya objek manusia. Sistem pendeteksi gerakan ini selanjutnya mendeteksi 1 manusia dan kelompok manusia dalam 1 frame di waktu yang bersamaan. Selanjutnya sistem akan menghitung jumlah manusia yang terdeteksi. Jika tidak terdapat manusia sistem tidak akan menghitung jumlah orang.

\section{METode PENELITIAN}

Dalam penelitian, sistem membandingkan keakuratan algoritma background subtraction dan optical flow untuk mendeteksi manusia dan menghitung jumlah manusia yang terdeteksi. Kedua algoritma tersebut memiliki proses-proses untuk mendapatkan hasil deteksi manusia.

A. Algoritma background subraction

Algoritma ini adalah algoritma pertama yang digunakan untuk mendeteksi manusia. Berikut adalah langkah-langkah proses dalam algoritma background subtraction untuk melakukan deteksi manusia.

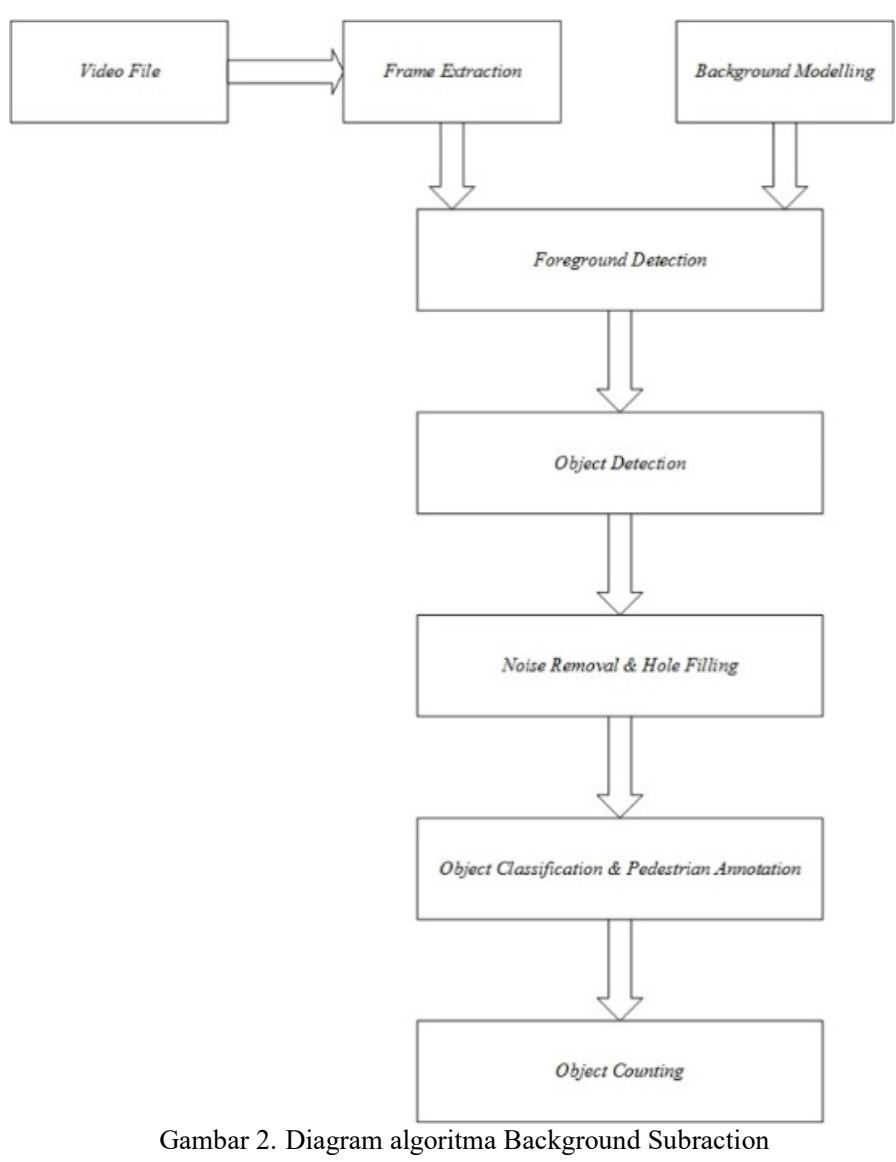

\section{1) Pre-processing}

Dalam tahap ini dilakukan proses pengubahan data mentah yang diambil dari kamera (atau alat lainnya) menjadi bentuk yang dapat dimengerti oleh komputer. Dalam tahap ini juga dilakukan noise removal dan eliminasi objek kecil pada gambar. Disini mathematical morphology yaitu transformasi Opening, digunakan untuk mengeliminasi objek kecil. Operasi morfologi merupakan teknik pengolahan citra digital dengan memakai bentuk objek sebagai pedoman [1]. Video to frame extraction merupakan proses awal yang dilakukan untuk mengekstrak dan membaca frame (gambar) yang terdapat dari dalam video masukan untuk dapat melakukan proses selanjutnta. Syntax pada matlab yang digunakan untuk mengekstrak video ke frame yaitu readFrame() [1].

\section{2) Background Modelling}

Pada tahap ini ditentukan sebuah model background yang konsisten Model harus tetap bisa beradaptasi dan mentoleransi saat adanya perubahan lingkungan, jugta tetap sensitif untuk mendeteksi adanya pergerakan dari objek yang relevan. Background modelling merupakan tahap untuk menentukan background. Background yang dipakai merupakan latar belakang tempat pengambilan video. Background yang ditentukan haruslah tidak terdapat objek manusia. Background ini harus bersifat statis yaitu tanpa berpindah tempat maupun bergerak. Model background 
yang digunakan harus konsisten dan tetap sensitif terhadap adanya pergerakan dari objek [4].

\section{3) Foreground detection}

Proses ekstraksi foreground dari background dilakukan dalam tahap ini. proses ini memiliki persamaan matematis yaitu:

$$
\mathrm{R}_{\mathrm{r}, \mathrm{c}}=\mathrm{I}_{\mathrm{r}, \mathrm{c}}-\mathrm{B}_{\mathrm{r}, \mathrm{c}}
$$

$$
\begin{aligned}
& \text { Ket: } \\
& \mathrm{R}=\text { hasil } \\
& \mathrm{I}=\text { gambar saat ini } \\
& \mathrm{B}=\text { background model } \\
& \mathrm{r}=\text { baris } \\
& \mathrm{c}=\text { kolom }
\end{aligned}
$$

Nilai R lalu dibandingkan dengan nilai threshold yang telah ditentukan, jika lebih besar dari nilai threshold maka piksel di I $(\mathrm{r}, \mathrm{c})$ dapat dianggap berbeda dengan piksel di $\mathrm{B}(\mathrm{r}, \mathrm{c})$. Nilai threshold adalah semacam nilai untuk menolerasi error yang mungkin terjadi, threshold sendiri dipakai untuk mengurangi error yang disebabkan noise pada gambar digital [1]. Pada penelitian ini dilakukan proses mengekstraksi foreground dari background. Foreground merupakan objek bergerak, dalam hal ini yaitu manusia.

\section{4) Object Detection}

Tahap ini yaitu mendeteksi dan menemukan adanya pergerakan dari objek di setiap frame. Tahap ini memakai metode Kalman filter dan algoritma blob analysis. Kalman filter (KF) adalah suatu metode estimasi variabel keadaan dari sistem dinamik stokastik linear diskrit yang meminimumkan kovariansi error estimasi [5]. Sedangkan blob analysis adalah algoritma yang digunakan untuk mendeteksi titik atau area pada sebuah citra yang berbeda baik warna maupun kecerahannya jika dibandingkan dengan sekitarnya.[6]

\section{5) Noise Removal dan Hole Filling}

Dalam tahap ini dilakukan proses penghilangan gangguan (noise removal) dan pengisian lubang (hole filling) pada citra. Citra hasil perlu dilakukan noise removal agar lebih baik. Selanjutnya hasil citra juga dilakukan proses pengisian (filling) karena masih terdapat banyak lubang (hole). Filling dilakukan dengan menutupi lubang-lubang kecil pada citra agar citra menjadi lebih halus. Proses Noise Removal dan Hole Filling ini menggunakan Operasi Morfologi.

\section{6) Object Classification dan Pedestrian Annotation}

Tahap klasifikasi objek merupakan tahap untuk membedakan mana objek manusia mana bukan. Pada tahap ini dilakukan seleksi pada objek dengan melihat ukuran setiap objek. Ukuran tersebut didapat dari mendeteksi garis batas (boundary) dari setiap objek yang terdeteksi. Boundary pada objek bertujuan untuk mendeteksi 1 objek manusia serta beberapa objek manusia yang berdekatan dengan lebih akurat. Setelah melalui tahap klasifikasi objek, objek pejalan kaki akan dibingkai dengan kotak berwarna hijau (rectangle). Kotak tersebut didapat dari nilai garis batas (boundary) terluar dari objek.

\section{7) Object Counting}

Pada tahap akhir yaitu menghitung berapa jumlah manusia yang terdeteksi. Jumlah tersebut didapat dari menghitung rectangle yang ada. Jika sistem masih belum mendeteksi dengan baik objek bergerak, sistem akan menghitungnya dengan memprediksinya (predicted). Jika sistem telah dengan baik mendeteksi objek yang bergerak, sistem akan langsung menghitungnya (detected).

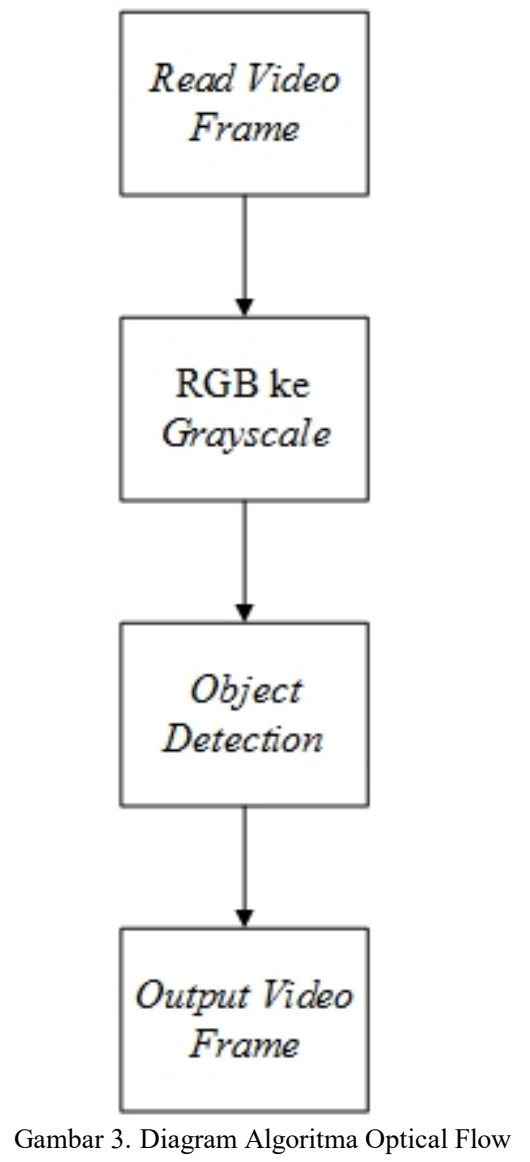

Secara lengkap proses background subtraction digambarkan melalui diagram pada Gambar 2. Pada algoritma background subtraction video rekaman yang diinput ke matlab pertama-tama diekstrak menjadi frameframe. Algoritma ini sebelumnya harus menentukan background (background modelling) agar bisa diproses ke tahap berikutnya. Selanjutnya adalah tahap foreground detection untuk memisahkan objek dari background. Setelah itu dilakukan pencarian pergerakan dari objek. Lalu dilakukan penghilangan noise serta pengisian agar citra lebih baik. Setelah itu dilakukan object classification dan pedestrian annotation untuk mengklasifikasi objek manusia dan bukan. Dan terakhir dilakukan tahap object counting yaitu menghitung jumlah objek manusia yang berhasil dideteksi.

\section{B. Algoritma Optical Flow}

Algoritma ini adalah algoritma kedua yang digunakan untuk mendeteksi manusia. Selanjutnya algoritma ini akan dibandingkan dengan algoritma pertama. 


\section{1) Read Video Frame}

Read Video frame merupakan proses awal yang dilakukan untuk membaca frame (gambar) yang terdapat dari dalam video masukan untuk dapat melakukan proses selanjutnya.

\section{2) RGB ke Grayscale}

RGB ke grayscale adalah proses untuk mengubah frame dalam video menjadi citra berwarna grayscale [6].

\section{3) Object Detection}

Tahap ini yaitu menemukan adanya objek dengan mendeteksi adanya pergerakan dari objek di setiap frame. Tahap ini memakai metode Horn-Schunck. Metode HornSchunck diimplementasikan untuk mendeteksi objek bergerak dengan melacak vektor gerakan objek tersebut [7].

\section{4) Output Video Frame}

Selanjutnya setelah diketahui adanya pergerakan dari suatu objek, sistem akan memberikan hasil keluaran pergerakan objek tersebut yang ditandai dengan adanya titik-titk dari satu frame ke frame berikutnya secara berkelanjutan. Gambar 3 menunjukan diagram dari proses algoritma optical flow Pada algoritma optical flow proses awal yang dilakukan yaitu membaca frame (gambar) yang terdapat dari dalam video masukan untuk dapat melakukan proses selanjutnta. Selanjutnya proses RGB ke grayscale yaitu proses untuk mengubah frame dalam video menjadi citra berwarna grayscale. Setelah itu tahap berikutnya yaitu menemukan adanya objek dengan mendeteksi adanya pergerakan dari objek di setiap frame. Selanjutnya sistem akan memberikan hasil keluaran pergerakan objek tersebut yang ditandai dengan adanya titik-titk dari satu frame ke frame.

\section{HASIL DAN PEMBAHASAN}

\section{A. Algoritma Background Subraction}

Algoritma background subtraction mendeteksi objek manusia dengan cara membandingkan gambar yang memiliki objek dengan gambar latar belakang yang tidak memiliki objek. Video rekaman dimasukkan ke syntax matlab dan diproses untuk mendeteksi objek manusia. Video yang direkam berdurasi 3 menit (180 detik). Lalu video tersebut dipecah menjadi frame-frame, dan menghasilkan total 5400 frame. Pencuplikan gambar dilakukan setiap 5 detik sekali atau setiap 150 frame sekali. Jumlah frame yang dicuplik yaitu 36. Pencuplikan dilakukan untuk selanjutnya dibandingkan dengan algoritma optical flow maupun dengan perhitungan manual dari video rekaman asli yang tidak diproses di matlab untuk menentukan tingkat keakuratannya dalam mendeteksi keberadaan manusia dan menghitung jumlah manusia yang terdeteksi.

Hasil cuplikan proses ditunjukan pada Gambar 4 yang didapat dari hasil mendeteksi keberadaan manusia menggunakan algoritma background subtraction. Warna hitam merupakan background. Sedangkan warna putih merupakan objek manusia dan pergerakannya yang terdeteksi, yang didapat dari hasil gambar background berobjek dengan dikurangi gambar background utuh tanpa objek. Pengurangan citra yang memiliki objek dengan citra background yang tidak memiliki objek yang telah ditentukan sistem sebelumnya, menghasilkan gambar keluaran seperti diatas. Frame yang dicuplik setiap 150 frame sekali yaitu yaitu frame ke- 150 sampai 5400 .
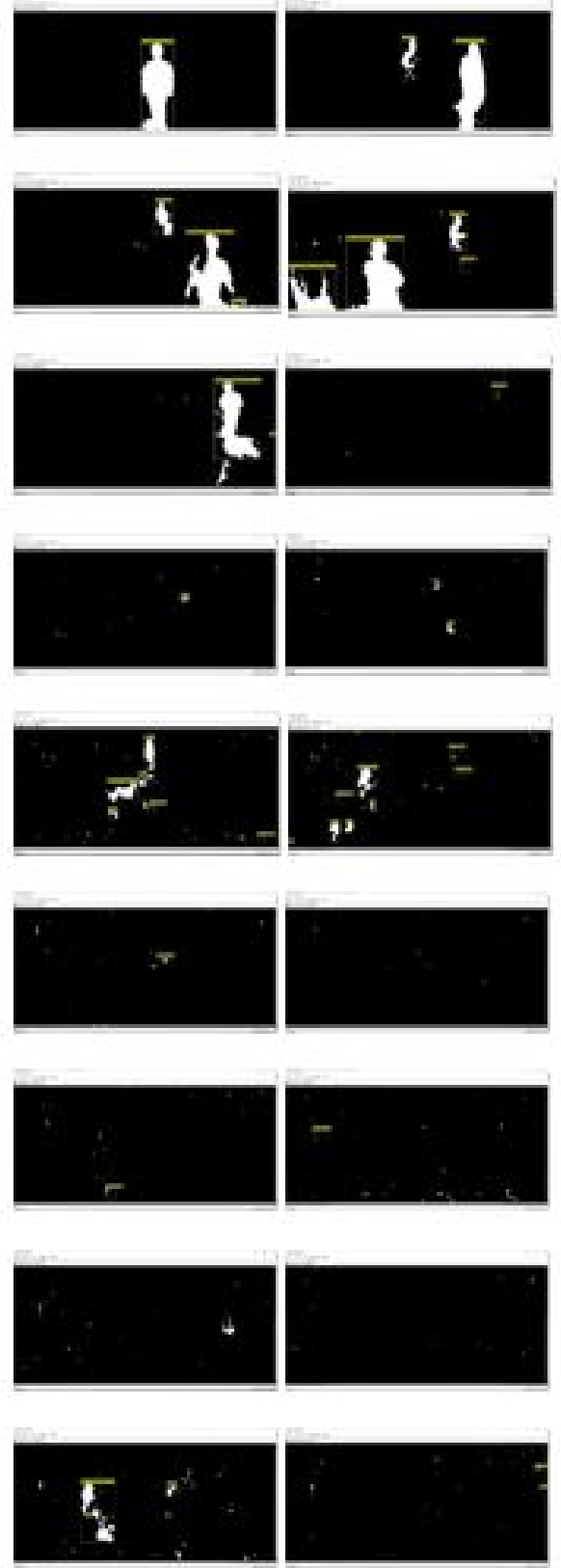

Gambar 4. Hasil deteksi manusia menggunakan algoritma Background Subtraction Black and White

Jumlah orang yang didapatkan pada frame ke-150 - 5400 adalah 1 sampai 1925 orang (predicted). Sistem akan langsung memberikan angka dari jumlah orang yang telah dideteksi dengan pasti. Sedangkan untuk jumlah orang yang belum diketahui dengan pasti sistem akan memberikan output angka jumlah orang beserta keterangan (predicted).

Gambar 5 adalah cuplikan gambar-gambar yang didapat dari hasil mendeteksi keberadaan manusia menggunakan algoritma background subtraction dengan warna original, tanpa adanya pengurangan antara gambar background berobjek dengan gambar background utuh tanpa objek. 

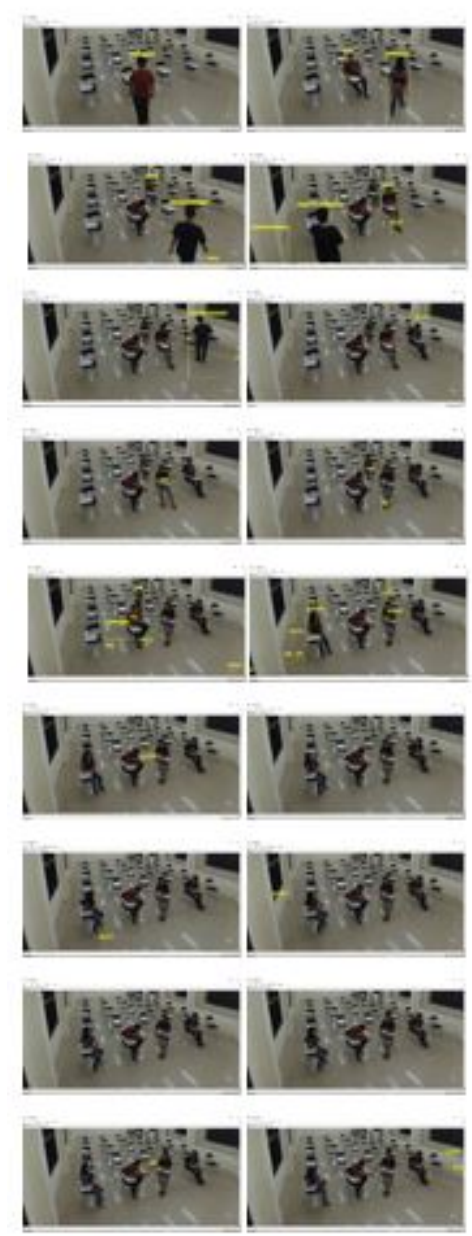

Gambar 5. Hasil deteksi manusia menggunakan algoritma Background Subtraction dengan warna original

\section{B. Algoritma Optical Flow}

Algoritma optical flow adalah aliran pergerakan dari sebuah objek yang bergerak. Video rekaman dimasukkan ke syntax matlab dan diproses untuk mendeteksi objek manusia. Video yang direkam berdurasi 3 menit (180 detik). Lalu video tersebut dipecah menjadi frame-frame, dan menghasilkan total 5400 frame.

Pencuplikan gambar dilakukan setiap 5 detik sekali atau setiap 150 frame sekali. Jumlah frame yang dicuplik yaitu 36. Pencuplikan dilakukan untuk selanjutnya dibandingkan dengan algoritma background subtraction maupun dengan perhitungan manual dari video rekaman asli yang tidak diproses di matlab untuk menentukan tingkat keakuratannya dalam mendeteksi keberadaan manusia dan menghitung jumlah manusia yang terdeteksi. Cuplikan gambar-gambar yang didapat dari hasil mendeteksi keberadaan manusia menggunakan algoritma optical flow ditunjukan pada Gambar 6 Terlihat bahwa background dan objek manusia berwarna grayscale sedangkan pergerakan objek manusia yang terdeteksi ditandai dengan titik-titik berwarna putih dari satu frame ke frame berikutnya secara berlanjut. Jika objek di dalam frame tidak bergerak tidak akan ditandai dengan titik-titik berwarna putih. Frame yang dicuplik setiap 150 frame sekali yaitu yaitu frame ke- 150 sampai 5400. Jumlah orang yang didapatkan pada frame ke-150 5400 adalah 1 sampai 3 orang.
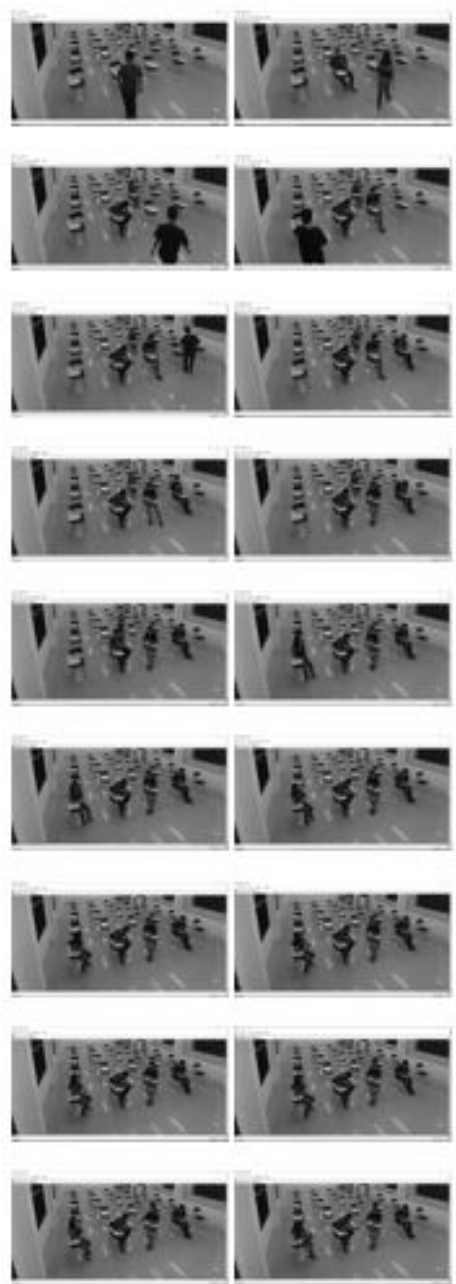

Gambar 6. Hasil deteksi manusia menggunakan algoritma Optical Flow

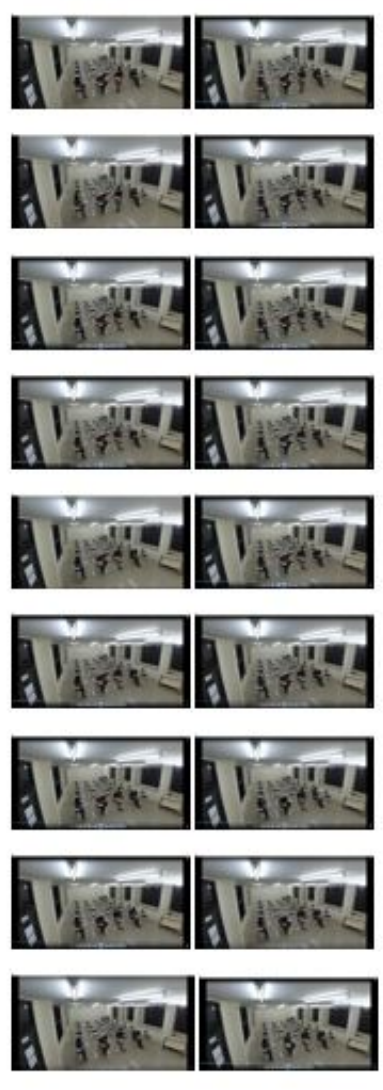

Gambar 7. Video original 
TABEL I

Hasil PERBANDINGAN Algoritma BACKGROUND SUBRACTION, AlgoritMa OPTICAL FLOW SERTA VIDEO ORIGINAL UNTUK MENDETEKS KEBERADAAN MANUSIA

\begin{tabular}{|c|c|c|c|c|c|}
\hline $\mathrm{s} /$ frame & $\begin{array}{l}\text { Background } \\
\text { Subraction }\end{array}$ & Detection & $\begin{array}{l}\text { Optical } \\
\text { Flow }\end{array}$ & Detection & $\begin{array}{c}\text { Original } \\
\text { Video }\end{array}$ \\
\hline $5 / 150$ & 1 & Detected & 1 & Detected & 1 \\
\hline $10 / 300$ & 5 & Detected & 2 & Detected & 2 \\
\hline $15 / 450$ & 17 & Detected & 3 & Detected & 3 \\
\hline $20 / 600$ & 32 & Detected & 3 & Detected & 4 \\
\hline $25 / 750$ & 32 & Detected & 2 & Detected & 4 \\
\hline $30 / 900$ & $\begin{array}{l}64 \\
\text { (predicted) }\end{array}$ & Detected & 4 & Detected & 4 \\
\hline $35 / 1050$ & 92 & Detected & 3 & Detected & 4 \\
\hline $40 / 1200$ & 103 & Detected & 3 & Detected & 4 \\
\hline $45 / 1350$ & 179 & Detected & 3 & Detected & 4 \\
\hline $50 / 1500$ & 257 & Detected & 3 & Detected & 4 \\
\hline $55 / 1650$ & 289 & Detected & 3 & Detected & 4 \\
\hline $60 / 1800$ & 0 & Undetected & 3 & Detected & 4 \\
\hline $65 / 1950$ & $\begin{array}{l}345 \\
\text { (predicted) }\end{array}$ & Detected & 1 & Detected & 4 \\
\hline $70 / 2100$ & $\begin{array}{l}363 \\
\text { (predicted) }\end{array}$ & Detected & 2 & Detected & 4 \\
\hline $75 / 2250$ & 0 & Undetected & 2 & Detected & 4 \\
\hline $80 / 2400$ & 0 & Undetected & 1 & Detected & 4 \\
\hline $85 / 2550$ & 582 & Detected & 3 & Detected & 4 \\
\hline $90 / 2700$ & $\begin{array}{l}635 \\
\text { (predicted) }\end{array}$ & Detected & 2 & Detected & 4 \\
\hline $95 / 2850$ & $\begin{array}{l}686 \\
\text { (predicted) }\end{array}$ & Detected & 3 & Detected & 4 \\
\hline $100 / 3000$ & $\begin{array}{l}779 \\
\text { (predicted) }\end{array}$ & Detected & 2 & Detected & 4 \\
\hline $105 / 3150$ & 845 & Detected & 4 & Detected & 4 \\
\hline $110 / 3300$ & 0 & Undetected & 1 & Detected & 4 \\
\hline $115 / 3450$ & 961 & Detected & 0 & Undetected & 4 \\
\hline $120 / 3600$ & 1051 & Detected & 1 & Detected & 4 \\
\hline $125 / 3750$ & 1102 & Detected & 1 & Detected & 4 \\
\hline $130 / 3900$ & 0 & Undetected & 1 & Detected & 4 \\
\hline $135 / 4050$ & 1232 & Detected & 3 & Detected & 4 \\
\hline $140 / 4200$ & 0 & Undetected & 2 & Detected & 4 \\
\hline $145 / 4350$ & 0 & Undetected & 3 & Detected & 4 \\
\hline $150 / 4500$ & 1501 & Detected & 3 & Detected & 4 \\
\hline $155 / 4650$ & 1709 & Detected & 4 & Detected & 4 \\
\hline $160 / 4800$ & 1602 & Detected & 2 & Detected & 4 \\
\hline $165 / 4950$ & $\begin{array}{l}1862 \\
\text { (predicted) }\end{array}$ & Detected & 3 & Detected & 4 \\
\hline $170 / 5100$ & 1933 & Detected & 2 & Detected & 4 \\
\hline $175 / 5250$ & $\begin{array}{l}2030 \\
\text { (predicted) }\end{array}$ & Detected & 1 & Detected & 4 \\
\hline $180 / 5400$ & $\begin{array}{l}1925 \\
\text { (predicted) }\end{array}$ & Detected & 3 & Detected & 4 \\
\hline
\end{tabular}

\section{Video original}

Video original merupakan video asli yang tidak dimasukkan ke dalam syntax matlab untuk diproses. Video asli ini akan dibandingkan dengan kedua algoritma diatas yaitu background subtraction dan optical flow untuk menentukan tingkat keakuratannya dalam mendeteksi keberadaan manusia dan menghitung jumlah manusia yang terdeteksi. Video yang direkam berdurasi 3 menit atau 180 detik. Pencuplikan gambar dilakukan setiap 5 detik sekali. Jumlah gambar yang dicuplik yaitu 36. Gambar 7 menunjukan cuplikan gambar-gambar dari video original. Gambar 7 merupakan gambar yang didapat dari hasil video original. Gambar yang dicuplik setiap 5 detik yaitu pada detik ke- 5 sampai menit ke- 3:00. Jumlah orang yang didapatkan pada detik ke-0:05 sampai menit ke 3:00 adalah 1 sampai 4 orang.
TABEL II

Hasil Perbandingan ALgORITMa BACKGROUND SUBRACTION, AlgORItMA OPTICAL FLOW SERTA VIDEO ORIGINAL UNTUK MENGHitung JUMLAH MANUSIA YANG TERDETEKSI

\begin{tabular}{|c|c|c|c|c|c|}
\hline s/frame & $\begin{array}{l}\text { Background } \\
\text { Subraction }\end{array}$ & Counting & $\begin{array}{l}\text { Optical } \\
\text { Flow }\end{array}$ & Counting & $\begin{array}{c}\text { Original } \\
\text { Video }\end{array}$ \\
\hline $5 / 150$ & 1 & True & 1 & True & 1 \\
\hline $10 / 300$ & 5 & False & 2 & True & 2 \\
\hline $15 / 450$ & 17 & False & 3 & True & 3 \\
\hline $20 / 600$ & 32 & False & 3 & False & 4 \\
\hline $25 / 750$ & 32 & False & 2 & False & 4 \\
\hline $30 / 900$ & $\begin{array}{l}64 \\
(\text { predicted })\end{array}$ & False & 4 & True & 4 \\
\hline $35 / 1050$ & 92 & False & 3 & False & 4 \\
\hline $40 / 1200$ & 103 & False & 3 & False & 4 \\
\hline $45 / 1350$ & 179 & False & 3 & False & 4 \\
\hline $50 / 1500$ & 257 & False & 3 & False & 4 \\
\hline $55 / 1650$ & 289 & False & 3 & False & 4 \\
\hline $60 / 1800$ & 0 & False & 3 & False & 4 \\
\hline $65 / 1950$ & $\begin{array}{l}345 \\
\text { (predicted) }\end{array}$ & False & 1 & False & 4 \\
\hline $70 / 2100$ & $\begin{array}{l}363 \\
\text { (predicted) }\end{array}$ & False & 2 & False & 4 \\
\hline $75 / 2250$ & 0 & False & 2 & False & 4 \\
\hline $80 / 2400$ & 0 & False & 1 & False & 4 \\
\hline $85 / 2550$ & 582 & False & 3 & False & 4 \\
\hline $90 / 2700$ & $\begin{array}{l}635 \\
\text { (predicted) }\end{array}$ & False & 2 & False & 4 \\
\hline $95 / 2850$ & $\begin{array}{l}686 \\
\text { (predicted) }\end{array}$ & False & 3 & False & 4 \\
\hline $100 / 3000$ & $\begin{array}{l}779 \\
\text { (predicted) }\end{array}$ & False & 2 & False & 4 \\
\hline $105 / 3150$ & 845 & False & 4 & True & 4 \\
\hline $110 / 3300$ & 0 & False & 1 & False & 4 \\
\hline $115 / 3450$ & 961 & False & 0 & False & 4 \\
\hline $120 / 3600$ & 1051 & False & 1 & False & 4 \\
\hline $125 / 3750$ & 1102 & False & 1 & False & 4 \\
\hline $130 / 3900$ & 0 & False & 1 & False & 4 \\
\hline $135 / 4050$ & 1232 & False & 3 & False & 4 \\
\hline $140 / 4200$ & 0 & False & 2 & False & 4 \\
\hline $145 / 4350$ & 0 & False & 3 & False & 4 \\
\hline $150 / 4500$ & 1501 & False & 3 & False & 4 \\
\hline $155 / 4650$ & 1709 & False & 4 & False & 4 \\
\hline $160 / 4800$ & 1602 & False & 2 & False & 4 \\
\hline $165 / 4950$ & $\begin{array}{l}1862 \\
\text { (predicted) }\end{array}$ & False & 3 & False & 4 \\
\hline $170 / 5100$ & 1933 & False & 2 & False & 4 \\
\hline $175 / 5250$ & $\begin{array}{l}2030 \\
\text { (predicted) }\end{array}$ & False & 1 & False & 4 \\
\hline $180 / 5400$ & $\begin{array}{l}1925 \\
\text { (predicted) }\end{array}$ & False & 3 & False & 4 \\
\hline
\end{tabular}

Berdasarkan tabel I terdapat pengujian menggunakan algoritma background subtraction dan algoritma optical flow lalu dibandingkan menggunakan video original untuk mengetahui tingkat keakuratan dalam mendeteksi keberadaan manusia. Algoritma background subtraction dan optical flow mencuplik pada frame ke- sampai ke5400, sedangkan video original dicuplik pada detik ke- 05, sampai menit ke 3:00. Detection akan detected apabila algoritma background subtraction maupun optical flow bisa mendeteksi keberadaan manusia dengan jumlah manusia $>$ 0 . Sedangkan detection akan undetected apabila algoritma background subtraction maupun optical flow tidak bisa mendeteksi keberadaan manusia dengan jumlah manusia $=$ 0 .

Berdasarkan tabel 2 terdapat pengujian menggunakan algoritma background subtraction dan algoritma optical flow lalu dibandingkan menggunakan video original untuk 
mengetahui tingkat keakuratan dalam menghitung keberadaan manusia yang terdeteksi. Pada algoritma background subtraction, sistem akan langsung memberikan angka dari jumlah orang yang telah dideteksi dengan pasti. Sedangkan untuk jumlah orang yang belum diketahui dengan pasti sistem akan memberikan output angka jumlah orang beserta keterangan (predicted).Algoritma background subtraction dan optical flow mencuplik pada frame ke- 150 , sampai ke- 5400, sedangkan video original dicuplik pada detik ke- 05 sampai menit ke 3:00. Counting akan true apabila algoritma background subtraction maupun optical flow bisa menghitung keberadaan manusia yang terdeteksi sama dengan jumlah manusia pada video original. Sedangkan counting akan false apabila algoritma background subtraction maupun optical flow menghitung keberadaan manusia yang terdeteksi tidak sama dengan jumlah manusian pada video original.

Hasil Mendeteksi Keberadaan Manusia:

1. Background Subraction

True detection : 29

$=\frac{\text { True det ection }}{\text { Total det ection }} \times 100 \%=\frac{29}{36} \times 1000 \%=80.56 \%$

False detection : 7

$=\frac{\text { False det ection }}{\text { Total det ection }} \times 100 \%=\frac{7}{36} \times 1000 \%=19.44 \%$

\section{Optical Flow}

True detection : 35

$$
=\frac{\text { True det ection }}{\text { Total } \operatorname{det} \text { ection }} \times 100 \%=\frac{35}{36} \times 1000 \%=97.22 \%
$$

\section{False detection : 1}

$$
=\frac{\text { True det ection }}{\text { True det ection }} \times 100 \%=\frac{1}{36} \times 1000 \%=2.78 \%
$$

Hasil untuk mendeteksi keberadaan manusia, algoritma background subtraction memiliki tingkat kebenaran sebanyak 29 detection yaitu $80.56 \%$ dan tingkat kesalahan sebanyak 7 detection yaitu $19.44 \%$. Sedangkan algoritma optical flow memiliki tingkat kebenaran sebanyak 35 detection yaitu $97.22 \%$ dan tingkat kesalahan sebanyak 1 detection yaitu $2.78 \%$.

Dari pengujian menggunakan algoritma background subtraction dan algoritma optical flow serta dibandingkan menggunakan video original didapatkan hasil menghitung keberadaan manusia yang terdeteksi seperti pada tabel I.

Hasil Menghitung Jumlah Manusia:

1. Background Subraction

True detection : 1

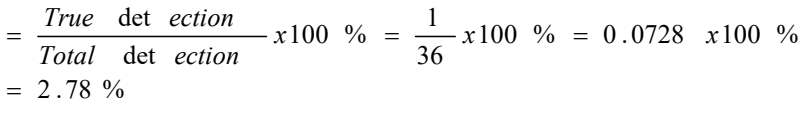

False detection : 35

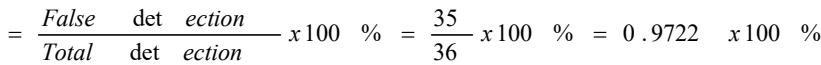

$=97.22 \%$

2. Optical Flow

True detection : 6

$=\frac{\text { True } \operatorname{det} \text { ection }}{\text { Total } \operatorname{det} \text { ection }} \times 100 \%=\frac{6}{36} \times 100 \%=0.1667 \times 100 \%$ $=16.67 \%$

False detection : 30

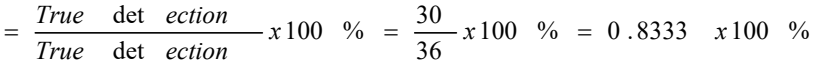
$=83.33 \%$

Selanjutnya hasil untuk menghitung jumlah manusia yang terdeteksi, algoritma background subtraction memiliki tingkat kebenaran sebanyak 1 yaitu $2.78 \%$ dan tingkat kesalahan sebanyak 35 yaitu 97.22\%. Sedangkan algoritma optical flow memiliki tingkat kebenaran sebanyak 6 yaitu $16.67 \%$ dan tingkat kesalahan sebanyak 30 yaitu $83.33 \%$.

Dari pengujian menggunakan algoritma background subtraction dan algoritma optical flow serta dibandingkan menggunakan video original didapatkan hasil menghitung keberadaan manusia yang terdeteksi seperti pada tabel I.

\section{KESIMPULAN}

Setelah melakukan penelitian ini dilakukan didapatkan hasil bahwa algoritma optical flow memiliki tingkat keakuratan yang lebih tinggi dari algoritma background subtraction. Hal ini didapat dari besarnya persentase deteksi untuk mendeteksi keberadaan manusia serta menghitung jumlah manusia tersebut. Dari hasil yang didapat untuk mendeteksi keberadaan manusia, algoritma background subtraction memiliki tingkat kebenaran sebanyak $80.56 \%$. Sedangkan algoritma optical flow memiliki tingkat kebenaran sebanyak $97.22 \%$. Selanjutnya hasil yang didapat untuk menghitung jumlah manusia yang terdeteksi, algoritma background subtraction memiliki tingkat kebenaran sebanyak $2.78 \%$. Sedangkan algoritma optical flow memiliki tingkat kebenaran sebanyak $16.67 \%$.

\section{KUTIPAN}

[1] Umam, K. dan Negara, B. S. 2016. Deteksi Obyek Manusia Pada Basis Data Video Mengounakan Metode Background Subtraction Dan Operasi Morfologi. http://ejournal.uinsuska.ac.id/index.php/coreit/article/download/2391/pdf 19 Maret 2017

[2] Ardhianto, E. dkk 2013. Implementasi Metode Image Subtracting Dan Metode Regionprops Untuk Mendeteksi Jumlah Objek Berwarna Rgb Pada File Video. http://www.unisbank.ac.id/ojs/index.php/fti1/article/view/1697 19 Maret 2017

[3] Umar, U. dkk 2011. Tracking Arah Gerakan Telunjuk Jari Berbasis Webcam Menggunakan Metode Optical Flow. http://repo.pens.ac.id/1447/1/[E-D303-4]_pp.249254 Tracking_Arah_Gerakan_Telunjuk_Jari_Berbasis_Webcam.p df 20 Mei 2017

[4] Solichin, A. dan Harjoko, A. 2013. Metode Background Subtraction Untuk Deteksi Objek Pejalan Kaki Pada Lingkungan Statis. https://media.neliti.com/media/publications/174588-IDmetode-background-subtraction-untuk-dete.pdf 19 Maret 2017

[5] Nugrahini, T. 2012. Perbandingan Metode Kalman Filter Dan Metode Ensemble Kalman Filter Dalam Mendeteksi Gangguan Konduksi Panas Pada Batang Logam. 
http://repository.unej.ac.id/bitstream/handle/123456789/6937/Tria $\% 20$ Nugrahini $\% 20-\% 20081810101012$.pdf?sequence $=1$ November 2017

[6] Samir, M. I.dkk Penerapan Algoritma Background Subtraction Untuk Tracking dan Klasifikasi Kendaraan. http://perpustakaan.fmipa.unpak.ac.id/file/ejurnal\%20ikhsan\%20065112282.pdf 13 November 2017

[7] Arioputra, D. 2012. Analisa Perbandingan Akurasi Metode Optical Flow Dan Gaussian Mixture Model Untuk Sistem Pemantau Lalu $\begin{array}{lll}\text { Lintas Berbasis } & \text { Computer Vision. }\end{array}$ http://lib.ui.ac.id/file?file=digital/20312331-S43308Analisa\%20perbandingan.pdf 13 November 2017

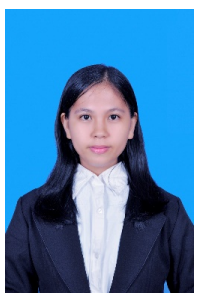

Karina Mariane Kaloh, merupakan anak tunggal dari pasangan Jopie Kaloh dan Flora Parera. Saya lahir di Manado, pada tanggal 15 Novermber 1995. Saya mulai menempuh pendidikan di TK Putra, Tikala. Selanjutnya saya melanjutkan pendidikan tingkat dasar di SD Katolik Frater Don Bosco Manado, masuk pada Juli 2001 dan lulus pada Juni 2007. Setelah itu menempuh pendidikan tingkat pertama di SMP Katolik Frater Don Bosco Manado, masuk pada Juli 2007 dan lulus pada Juni 2010. Lalu saya menempuh pendidikan tingkat atas masih di sekolah yang sama yaitu di SMA Katolik Frater Don Bosco Manado, masuk pada Juli 2010 dan lulus pada Juni 2013.

Pada Juli 2013 saya melanjutkan pendidikan ke salah satu perguruan tinggi negeri yang berada di Manado yaitu Universitas Sam Ratulangi Manado. Saya mengambil Program Studi S-1 Teknik Informatika di Jurusan Teknik Elektro Fakultas Teknik.

Pada Juli 2016 saya melakukan Kerja Praktek di Kantor Badan Penanggulangan Bencana Daerah Propinsi Sulawesi Utara. Dan pada April 2017 saya melakukan Kuliah Kerja Nyata Terpadu Angkatan 114 di Desa Tolok Kecamatan Tompaso Kabupaten Minahasa. Pada Mei 2017, penulis membuat skripsi demi memenuhi syarat memperoleh gelar Sarjana (S1) dengan penelitian berjudul Perbandingan Algoritma Background Subtraction Dan Optical Flow Untuk Deteksi Manusia, yang telah dibimbing oleh dua dosen pembimbing yaitu Dr. Eng. Vecky C.
Poekoel, ST., MT. dan Muhamad D. Putro, ST., M.Eng. Sehingga pada Januari 2018 penulis resmi lulus dari Program Studi Teknik Informatika Jurusan Elektro Fakultas Teknik Universitas Sam Ratulangi Manado dan menyandang gelar Sarjana Komputer dengan predikat Sangat memuaskan. 
